\section{Exemption from prescription charges}

DeAr Sirs

Vincenti writes (Psychiatric Bulletin, July 1992, 16, 444) that sufferers of recurrent depression should be made exempt from prescription charges.

I argued that lithium carbonate be made exempt some years ago and was informed that as recurrent depressive patients did not have a deficiency disease or a recognised physical abnormality similar to diabetes, hypothyroidism or epilepsy, then a case could not be made for exemption. The real reason seems economic and is exemplified by the fact that I persuaded the DHSS to make food supplements prescribable for anorexia nervosa in 1982 as the numbers are small. But if one wishes to use food supplements to control calorie intake for overweight patients, or to supplement the poor diet of drug addicts, then the same supplements are not prescribable because the numbers would make it uneconomic.

I would suggest Professor Sims takes into account the political problems when he attempts to come to a decision at the Executive and Finance Committee of the College.

\section{Burnley General Hospital Burnley BB10 2PQ}

M.A. LAUNER

(See Professor Sims' letter, Psychiatric Bulletin, November 1992, 16, 724).

\section{Psychiatry and the 'Old South Africa'}

\section{DeAr Sirs}

The recent report on the parlous state of psychiatry in the 'New South Africa' (Psychiatric Bulletin, June $1992,16,343-345$ ) and an account of the horrors of working in Soweto's, Baragwanath Hospital by a surgical officer (Goodman, 1992) prompted my own recollections of psychiatric care in that same hospital in the 'Old South Africa'.

Baragwanath is perhaps the largest hospital in the southern hemisphere serving Soweto's teeming population of three million. While a medical officer in one of the three professorial units of medicine for nine months in 1985 just prior to the State of Emergency I saw every bed, and the mattress between each bed, filled with patients. Technical resources and medical staffing were also stretched, and had been so for years. The work for all staff was mentally and physically exhausting. Yet there was a profound belief in providing the best possible medicine. This determination coupled with both the adversity and the vast resources of clinical material produced considerable medical expertise. There was quality in all medical specialities but onepsychiatry.
All patients were sent through casualty to either duty medical or surgical teams. Psychiatric patients were 'medical' and like most others presented late in the course of their disease. Neurotic illnesses were rarely seen. Frankly psychotic men and women were brought down from casualty, often terrified and aggressive, and requiring considerable restraint or a straitjacket. If one happened to break free a gang of nurses abandoning their duties would give chase with squeals of laughter. These nurses received minimal psychiatric training.

In the chaotic atmosphere of the admission ward medical staff were extremely pressed for time. Although obviously patients needed to be calmed and given an explanation of what was happening, this often proved to be impossible. Doctors rarely spoke Zulu well enough if the patient spoke no English. Patients were restrained and given the most powerful anti-psychotic at hand.

Once transferred to the ward they were placed in a cot with leg and arm restraints. Despite the size of Baragwanath there was no psychiatric department. They would await referral to the psychiatrist who visited the hospital twice weekly, while they remained on the ward heavily sedated. Later they were transferred to a psychiatric hospital.

There was no justification for this travesty of psychiatric care based on the pressure of numbers of patients with life-threatening illnesses. Apartheid fosters and creates ill-health, both physical and mental. Baragwanath seemed for many to epitomise the war against medical apartheid, but alas, there was no psychiatric front. Existing resources were least available to psychiatry.

Despite the inconceivable changes that have taken place since 1985 such as the releasing of imprisoned ANC activists, little will have changed for the psychiatric patient and may not for some years. For them New South Africa will be a new label on old wine.

Child \& Family Psychiatric Unit

LAURENCE SHELdON

5 Collingham Gardens.

London SW5 OHR

\section{Reference}

Goodman, D. (1992) All in a day's work. British Medical Journal, 304, 1061-1062.

\section{Confused wandering}

Dear Sirs

Kathleen Dougan and Carrick McDonald (Psychiatric Bulletin, August 1992, 16, 478) present further evidence that wandering does not increase around twilight as has been claimed to be the case. It is worth drawing attention to a much older study by 
Cameron (1941) who looked at the wandering confusion allegedly shown at night by 'senile' patients. He showed that the same disorganised behaviour could be created during the daytime by placing the patient in a darkened room. Building on this he speculated that confused behaviour occurred because the 'senile' patient could not maintain a spatial image or representation of the surroundings in the absence of repeated visual stimulation.

The claimed 'sundown' effect could therefore possibly relate to a real phenomenon which involves changes in the level of background illumination rather than the time of 'sundown' per se. Since patients are typically studied in residential units which are likely to have adequate artificial lighting, the association of the actual loss of illumination with sundown has been lost. It may be that confused wandering is more likely to occur in patients with dementia when background illumination is poor.

Department of Clinical Psychology

E. Miller

University of Leicester

Leicester LEI 7RH

\section{Reference}

Cameron, D. E. (1941) Studies in senile nocturnal delirium. Psychiatric Quarterly, 15, 47-53.

\section{Predictions of the demise of psychiatry}

\section{Dear Sirs}

At a recent meeting of the Royal College of General Practitioners, Professor Anthony Clare said that, given certain conditions, he anticipated that "... psychiatry might well disappear within 30 years". Reviewing the 'threat' that psychiatry is thought to be under, Cawley (1990) wrote: "The crucial question is this: what do psychiatrists do that others cannot do - individually or collectively?"'

I have a few 'questions and answers' of my own, in response.

Will there still be people suffering from mental illnesses in $\mathbf{3 0}$ years time? We have no reason at present to believe that these disorders will disappear in the near future.

Do we anticipate that the mentally ill will be looked after in the same facilities as the physically ill? Experience has demonstrated that psychiatric and non-psychiatric patients cannot be managed in the same facilities, in hospital or in the community.

Do we expect that in-patient facilities will remain part of the future provision for the care of the mentally ill? Undoubtedly so, 'community care' notwithstanding, there will always be illnesses of such severity that they cannot be managed other than on an in-patient basis.
Do we expect that doctors will have a role in the diagnosis and treatment of mental illness in the future? If so, which doctors will provide this service? It takes medical expertise to identify the underlying condition. Besides, assessment of psychopathology of the individual patient requires more training in psychiatry than GPs, or other physicians receive during their training. So there will need to be doctors who specialise in the care of the mentally ill.

If neurochemical and neurophysiological research should discover that mental disorders all have an organic basis, what difference would that make to the manifestations and management of these disorders? None. So psychiatry is not under threat at all.

Clare (personal communication, 1992) stated: "The psychiatrist is fast becoming in certain instances a sort of administrative supervisor, shuttling patients from one location to another (e.g. from the mental hospital to community facilities), more of a managerial expert than a true physician. Whether psychiatry should continue as a specialty or not I left open. Indeed I am myself of two minds. If I was confident that, for example, my colleagues in general medicine, general practice, geriatrics and allied fields really took the psychological aspects of medicine seriously, then I suppose I would not regret the passing of psychiatry as a specialty."

The concern about the role of psychiatry, and the responsibilities of psychiatrists, is genuine but is the conclusion valid?

Predictions of the demise of psychiatry as a medical specialty in advance of the disappearance of mental illness make us think about what we are doing, why, how and to what effect we are doing it. Nevertheless, in my view psychiatry will disappear when, and only when, there is no longer a requirement for psychiatrists; that is, when mental illness no longer occurs.

Grovelands Priory Hospital

IKECHUKWU O. AZUONYE

The Bourne, Southgate

London N146RA

\section{Reference}

CAWLEY, R. H. (1990) Educating the psychiatrist of the 21 st century. British Journal of Psychiatry, 157, 174-181.

\section{$A$ 'dementia helpline'-care for the carers?}

Dear Sirs

Carers of demented elderly people report a larger number of problems and greater strain than other 